\title{
Fall concern about older persons shifts to carers as changing health policy focuses on family, home-based care
}

Seng Giap Marcus $\underline{\text { Ang }}{ }^{1}$, BSc(Hons), Anthony Paul $\underline{\text { O’Brien }}^{1}$, PhD, RN, Amanda Wilson ${ }^{1}$, MCA, PhD

\begin{abstract}
With the Singaporean population ageing at an exponential rate, home carers are increasingly becoming essential partners in fall prevention and care delivery for older persons living at home and in the community. Singapore, like other Asian countries, regards the family as the main support structure for the older person, and national policies have been implemented to support this cultural expectation. Family carers experience similar concerns as older persons with regard to fall risk, and identifying and addressing these concerns can potentially lower fall risk and improve fall prevention for older persons. It is timely to remind ourselves - as concern about falls in older persons begins to shift to carers - to incorporate the influence of Asian cultural values and unique family dynamics of outsourcing family caregiving, in the management of older persons' fall risk in the community.
\end{abstract}

Keywords: carers, fall concern, fall prevention, older persons, Singapore

\section{INTRODUCTION}

Singapore, like other Asian countries, regards the family as the main support structure for older people. ${ }^{(1,2)}$ Recently, national policies have been implemented to encourage families to undertake the role of primary care provider. These policies, which address the distribution of financial responsibilities, have not been well studied for their societal impact and success. ${ }^{(1)}$ Policies such as subsidised public housing, income tax relief for children staying with their parents and the Maintenance of Parents Act reinforce and support the cultural expectations that children are obligated and expected to look after their parents. ${ }^{(1,3)}$ These expectations imply that the costs and burden of care for older people at risk of falls will be largely family-based. The family system must, therefore, be adequately prepared, supported and resourced to take on the challenges of caregiving with accessible community support. Shortages and the high cost of aged care community services that provide full-time care have led to many families having to engage foreign domestic workers (FDWs) to care for their dependents at home. ${ }^{(2,4)}$ This shift in the provision of care at home for older people is evidenced in a recent national survey of Singaporeans, which indicated that up to $50 \%$ of families relied on FDWs. ${ }^{(4)}$ The influence of Asian cultural values and the unique dynamics of extended family caregiving are important considerations in exploring the impact of carers' fall concerns in Singapore.

\section{DOMESTIC FALLS AMONG OLDER PERSONS}

Older persons experiencing domestic falls are an increasing concern in Singapore. Retrospective analyses of admissions to the emergency department suggest that $85.3 \%$ of the 720 elderly patients who were seen for injuries during a six-month study period had sustained their injuries as a consequence of falls in their homes. ${ }^{(5)}$ More than half $(67.9 \%)$ of these presentations required hospitalisation. ${ }^{(5)}$ Analysis of trauma cases admitted to an acute care Singapore hospital also found that older adults are more prone to falls that result in head injuries. ${ }^{(6)}$ The impact of domestic falls was exacerbated by a $4 \%$ increase in the proportion of older persons experiencing a dwindling resident old-age support ratio (persons aged 20-64 years per resident aged $\geq 65$ ) from 7.8 to 5.4 between 2006 and 2016. ${ }^{(7)}$ With the growing ageing population and the deleterious effect of fallrelated injuries, home carers are increasingly being recognised as essential partners in fall prevention and care delivery for older people in the community. In this climate of concern for older people's wellbeing, the priority is for health professionals to better understand the impact and effect of falls in older persons on their carers, and how this affects the way they might prevent and protect older persons from falls during their day-to-day care.

\section{FALL CONCERN AMONG CARERS}

Carers may experience similar fall concern as older persons with regard to the risk of falling. ${ }^{(8)}$ Due to the lack of local research on carers' fall-related concerns, inferences were made from overseas studies conducted in cities that are similar to Singapore. A prospective study of 96 pairs of carers and care recipients in Melbourne, Australia, found that carers reported a significant increase in caregiver burden after the older person had had their first fall. ${ }^{(8)}$ Similar results were also found in a large crosssectional study of 1,874 community-dwelling older persons in Japan. ${ }^{(9)}$ In this study, a history of falls in the person being cared for was associated with increased caregiver burden, even after controlling for functional status and comorbidities. ${ }^{(9)}$ Carers of persons who had fallen subsequently changed their social and 
work engagements for fear of leaving their care recipients alone. ${ }^{(8)}$ Older people can require higher levels of care following falls or progression of illness that causes falls. ${ }^{(8)}$ Among Asian carers in general, societal expectations of filial piety can serve as both a motivator for caregiving and a cause of stress among those who feel that they are unable to fulfil this role. ${ }^{(10)}$ In 2011, there were approximately 198,000 FDWs, mostly from the Philippines and Indonesia, working in Singapore, and this number is projected to increase to 300,000 in $2030 .{ }^{(11,12)}$ As the country becomes increasingly dependent on FDWs for home caregiving, healthcare professionals need to take into account their understanding of falls and fall concern during the management of older persons' health and safety. Yet, understanding their concerns can be complex and challenging, as the FDWs have to cope with the responsibilities of being the homemaker and full-time family carer. ${ }^{(11)}$

\section{CARERS PREVENTING FALLS}

Increasingly, fall prevention programmes are designed to include carers because of their close involvement in delivery of care for older persons. One study on the efficacy of a fall prevention programme for cancer patients reported that involving family carers significantly improved fall risk awareness and fall prevention knowledge. ${ }^{(13)}$ Another study assessing the impact of fear of falling among family caregivers on the functional recovery of hip fracture in older persons demonstrated that carers had significantly higher fall-related concerns than the older persons. ${ }^{(14)}$ Furthermore, there was a significant correlation between a greater difference in fear of falling (between the carers and older persons) and a longer recovery period in the older persons. ${ }^{(14)}$ Another study hypothesised that this outcome was due to overprotective carers who are excessively supportive, taking away the older person's independence. ${ }^{(15)}$ This concept is supported by a longitudinal study that investigated the impact of professional carers' fear of falls on the residents' functional ability and falls in long-term care facilities. ${ }^{(16)}$ In this study, the nurses' and nursing aides' fear of patients experiencing pain and falls was a significant predictor for the use of restraints or restrictions, which in turn led to functional deterioration and injurious falls. ${ }^{(16)}$ While the study findings discussed here do not indicate causation and are not generalisable to other populations, there was a significant correlation between the impact of carers' fall concern and the quality of care. Therefore, addressing carers' fall concern is an important element in fall prevention among older persons. This is especially relevant in a climate of global ageing, where alternatives to placement in aged care facilities may be limited.

\section{CONCLUSION}

It appears that carers' fall concern plays an important role in the prevention of falls among older persons in the community. This concern may directly influence perceptions of fall risk among carers and older persons, and determine their motivation to progressively and continuously adopt preventive behaviours. The emphasis on filial piety care does not necessarily mean that the care burden falls on the family members, as FDWs are increasingly employed as surrogate caregivers for older persons at home. Yet, this increasing reliance on FDWs for the delivery of care may indicate that families need more support from healthcare services, perhaps delivered directly to the home of the older persons who are at risk of falling. Given that carers could be affected by fall concern, the psychological impact on FDWs is substantial, if not even more significant. Being paid carers, FDWs may be caught in a dilemma between following the instructions of the older persons, who are often their employers, and executing adequate fall preventive measures. Yet, when the older persons fall, FDWs are likely to be accused of being negligent in the care provided. Rather than entrusting the entire delivery of care to families and, indirectly, to FDWs, the ministry and healthcare professionals need to ensure that adequate support is given to families caring for older persons at home. Such support can include increased funding to caring groups that support family caregiving, subsidies for utilisation of home nursing services, aged care community nurse support visits and rapid response services for carers looking after older persons at home. Identifying and addressing carers' needs in the delivery of community care could potentially reduce the reliance on institutional care facilities and allow older persons to age in the community. ${ }^{(17)}$

\section{ACKNOWLEDGEMENT}

This study is supported by an Australian Government Research Training Program Scholarship.

\section{REFERENCES}

1. Mehta KK. A critical review of Singapore's policies aimed at supporting families caring for older members. J Aging Soc Policy 2006; 18:43-57

2. Yeoh BS, Huang S. Foreign domestic workers and home-based care for elders in Singapore. J Aging Soc Policy 2010; 22:69-88.

3. Housing and Development Board, Singapore. Living with/near parents or married child. Available at: http://www.hdb.gov.sg/cs/infoweb/residential/ buying-a-flat/resale/living-with-near-parents-or-married-child. Accessed February 14, 2017.

4. Østbye T, Malhotra R, Malhotra C, Arambepola C, Chan A. Does support from foreign domestic workers decrease the negative impact of informal caregiving? Results from Singapore survey on informal caregiving. J Gerontol B Psychol Sci Soc Sci 2013; 68:609-21.

5. Yeo YY, Lee SK, Lim CY, Quek LS, Ooi SB. A review of elderly injuries seen in a Singapore emergency department. Singapore Med J 2009; 50:278-83.

6. Wui LW, Shaun GE, Ramalingam G, Wai KM. Epidemiology of trauma in an acute care hospital in Singapore. J Emerg Trauma Shock 2014; 7:174-9.

7. Department of Statistics Singapore. Population Trends. Available at: http:// www.singstat.gov.sg/statistics/visualising-data/storyboards/population-trends. Accessed February 14, 2017.

8. Dow B, Meyer C, Moore KJ, Hill KD. The impact of care recipient falls on caregivers. Aust Health Rev 2013; 37:152-7.

9. Kuzuya M, Masuda Y, Hirakawa Y, et al. Falls of the elderly are associated with burden of caregivers in the community. Int J Geriatr Psychiatry 2006; 21:740-5.

10. Ng HY, Griva K, Lim HA, Tan JY, Mahendran R. The burden of filial piety: a qualitative study on caregiving motivations amongst family caregivers of patients with cancer in Singapore. Psychol Health 2016; 31:1293-310.

11. The Singapore National Committee for the United Nations Development Fund for Women, Humanitarian Organisation for Migration Economics, Transient Workers Count Too. Made to work: attitudes towards granting regular days off to migrant domestic workers in Singapore. Available at: http://twc2.org.sg/ wp-content/uploads/2011/12/Madetowork-Dayoff-Report-2011.pdf. Accessed February 14, 2017

12. National Population and Talent Division, Prime Minister's Office, Singapore. Projection of foreign manpower demand for healthcare sector, construction workers and foreign domestic workers. Available at: https://www.nptd.gov.sg/ PORTALS/O/NEWS/OP_PROJE.PDF. Accessed February 14, 2017.

13. Potter $P$, Pion $S$, Klinkenberg D, Kuhrik M, Kuhrik N. An instructional DVD fall-prevention program for patients with cancer and family caregivers. Oncol Nurs Forum 2014; 41:486-94.

14. Shen J, Hu F, Liu F, Tong P. Functional restriction for the fear of falling in family 
caregivers. Medicine (Baltimore) 2015; 94:e1090.

15. Honaker JA, Kretschmer LW. Impact of fear of falling for patients and caregivers: perceptions before and after participation in vestibular and balance rehabilitation therapy. Am J Audiol 2014; 23:20-33.

16. Fitzgerald TG, Hadjistavropoulos T, MacNab YC. Caregiver fear of falling and functional ability among seniors residing in long-term care facilities. Gerontology 2009; 55:460-7.

17. Ministry of Health, Singapore. Nursing home capacity and demand. Available at: https://www.moh.gov.sg/content/moh web/home/pressRoom/Parliamentary QA/2017/nursing-home-capacity-and-demand.html. Accessed May 8, 2017. 